\title{
Strengthened Oxygen Oxidation of Ferrous Ions by a Homemade Venturi Jet Microbubble Generator towards Iron Removal in Hydrometallurgy
}

\author{
Xinzhuang Fu ${ }^{1}$, Zhen Niu ${ }^{1}$, Min Lin ${ }^{2}$, Ya Gao ${ }^{1}$, Wei Sun ${ }^{1}$ and Tong Yue ${ }^{1, *(D)}$ \\ 1 School of Minerals Processing and Bioengineering, Central South University, Changsha 410083, China; \\ f_xinzhuang83@csu.edu.cn (X.F.); zhenniu@csu.edu.cn (Z.N.); gaoya2019@csu.edu.cn (Y.G.); \\ sunmenghu@csu.edu.cn (W.S.) \\ 2 Sino Environment Engineering Co., Ltd., Guangzhou 510663, China; linmin8512@139.com \\ * Correspondence: yuetong@csu.edu.cn
}

check for updates

Citation: Fu, X.; Niu, Z.; Lin, M.; Gao, Y.; Sun, W.; Yue, T. Strengthened Oxygen Oxidation of Ferrous Ions by a Homemade Venturi Jet Microbubble Generator towards Iron Removal in Hydrometallurgy. Minerals 2021, 11, 1342. https://doi.org/min11121342

Academic Editor: Kenneth N. Han

Received: 28 October 2021

Accepted: 23 November 2021

Published: 29 November 2021

Publisher's Note: MDPI stays neutral with regard to jurisdictional claims in published maps and institutional affiliations.

Copyright: (c) 2021 by the authors. Licensee MDPI, Basel, Switzerland. This article is an open access article distributed under the terms and conditions of the Creative Commons Attribution (CC BY) license (https:// creativecommons.org/licenses/by/ $4.0 /)$.

\begin{abstract}
Iron normally exists in the form of ferrous ion $\left(\mathrm{Fe}^{2+}\right)$ in primary ore deposits of valuable metals. To remove iron from hydrometallurgical leaching solution or suspension by precipitation, ferrous ion should be oxidized to ferric ion $\left(\mathrm{Fe}^{3+}\right)$ first. Due to the low oxidation rate of $\mathrm{Fe}^{2+}$ by the traditional oxygen oxidation method, industry has to use more agitating barrels, steam, and compressed gas, as well as a larger workshop area, which dramatically increases the equipment investment and operation costs. In this study, a strengthened oxygen oxidation method for $\mathrm{Fe}^{2+}$ using a homemade venturi jet microbubble generator is proposed. Microbubbles of air, oxygen, or oxygen-enriched air can be formed in the leaching solution or suspension, which can greatly improve the dissolved oxygen content in the solution and increase the gas-liquid contact area, thereby accelerating the oxygen oxidation rate of $\mathrm{Fe}^{2+}$ to $\mathrm{Fe}^{3+}$ and realizing the rapid iron removal of the leaching solution or suspension. By measuring the residual concentration of $\mathrm{Fe}^{2+}$ in the solution after oxidation reaction, it was found that the pump power, solution temperature, $\mathrm{pH}$, concentration of $\mathrm{Cu}^{2+}$, and solution flow rate had great effects on the oxidation performance of the produced microbubble. By analyzing the images of the microbubbles and measuring the dissolved oxygen content in the solution, it is confirmed that the accelerated oxidation reaction rate of $\mathrm{Fe}^{2+}$ using the new proposed method was mainly due to the increase of the dissolved oxygen amount in the solution. Moreover, this method can significantly increase the purification depth of iron ion, expand production capacity, and decrease energy consumption.
\end{abstract}

Keywords: iron removal; oxygen oxidation of ferrous ion; venturi jet; microbubble

\section{Introduction}

The concentrate of zinc, nickel, copper, cobalt, manganese, and other non-ferrous metals normally contains a small amount of iron ore [1-3]. In hydrometallurgy of those metal ores, iron ions will inevitably enter the leaching solution. The iron ions in leaching solutions must be removed before subsequent electrodeposition and purification processes [4]. Iron can be removed by various methods, among which precipitation is the most widely used in the hydrometallurgy industry. The use of jarosite, goethite, and hematite precipitation methods for iron removal has been widely reported [5-11]. In these methods, ferric ions $\left(\mathrm{Fe}^{3+}\right)$ in solution are hydrolyzed under different conditions, such as temperature, $\mathrm{pH}$, and salt composition, to form corresponding precipitates of iron salt, thereby achieving the purpose of iron purification [12].

Metal sulfide ore or carbonate minerals, such as sphalerite, nickel sulfide ore, chalcopyrite, rhodochrosite, etc., are common ore materials used in hydrometallurgy. Iron in these primary ore deposits normally exists in the form of ferrous ion $\left(\mathrm{Fe}^{2+}\right)$. In fact, raw ore material is sometimes pretreated by reduction roasting before hydrometallurgy, such 
as fuming roasting of zinc iron spinel (zinc calcine), low nickel matte production from nickel sulfide ore, etc. [13]. The reduction atmosphere in the roasting process also ensures the existence of iron in the form of $\mathrm{Fe}^{2+}$. In order to remove iron by precipitation, $\mathrm{Fe}^{2+}$ should be oxidized to $\mathrm{Fe}^{3+}$ first. Oxygen, air, and oxygen-enriched air are commonly used oxidants in industry. Manganese dioxide (pyrolusite) and hydrogen peroxide, which are more expensive, are also used in special cases [14,15].

In the oxidation process of ferrous sulphate by molecular oxygen, the overall reaction is usually considered to have three important physicochemical steps, shown below as Equations (1)-(3) [16]:

Step 1: oxygen absorption:

$$
\mathrm{O}_{2}(\mathrm{~g}) \rightarrow \mathrm{O}_{2}(\mathrm{aq})
$$

Step 2: hydrolyzation of ferrous ions:

$$
\mathrm{Fe}^{2+}+2 \mathrm{H}_{2} \mathrm{O} \rightarrow \mathrm{Fe}(\mathrm{OH})_{2}+2 \mathrm{H}^{+}
$$

Step 3: homogeneous oxidation of ferrous ions:

$$
4 \mathrm{Fe}(\mathrm{OH})_{2}+\mathrm{O}_{2}(\mathrm{aq})+2 \mathrm{H}_{2} \mathrm{O} \rightarrow 4 \mathrm{Fe}(\mathrm{OH})_{3}
$$

Overall reaction as Equation (4):

$$
4 \mathrm{Fe}^{2+}+\mathrm{O}_{2}(\mathrm{aq})+10 \mathrm{H}_{2} \mathrm{O} \rightarrow 4 \mathrm{Fe}(\mathrm{OH})_{3}+8 \mathrm{H}^{+}
$$

The oxidation rate of ferrous ions was determined by the concentration of ferrous ions $\left(\left[\mathrm{Fe}^{2+}\right]\right)$, oxygen partial pressure $\left(\mathrm{P}_{\mathrm{O} 2}\right)$, concentration of ferrous sulfate $\left(\left[\mathrm{FeSO}_{4}\right]\right)$, concentration of copper sulfate $\left(\left[\mathrm{CuSO}_{4}\right]\right)$, and temperature $(T)$. The rate law was proposed as Equation (5) [17]:

$$
\frac{-d\left[\mathrm{Fe}^{2+}\right]}{d t}=\left(k_{1}\left[\mathrm{Fe}^{2+}\right]^{2} P_{\mathrm{O}_{2}}+k_{2}\left[\mathrm{Fe}^{2+}\right]\left[\mathrm{FeSO}_{4}\right] P_{\mathrm{O}_{2}}+k_{3}\left[\mathrm{FeSO}_{4}\right]^{2} P_{\mathrm{O}_{2}}\right)\left(1+0.5\left[\mathrm{CuSO}_{4}\right]^{0.5}\right) e^{-9660\left(\frac{1}{T}-\frac{1}{423.15}\right)}
$$

In industrial production, a blower is normally used to pressurize and blow oxygen, air, or oxygen-enriched air into the leaching solution through an air distributor or air distribution pipe installed at the bottom or wall of the mixing drum. However, the obtained bubble has the disadvantages of large bubble size, small gas-liquid contact area, and low pressure, which lead to a low dissolving rate of oxygen in the solution with the utilization rate of oxygen less than $10 \%$. This makes the oxidation rate of $\mathrm{Fe}^{2+}$ in the solution slow, so industry has to use several large stirring tanks to prolong the oxidation time of $\mathrm{Fe}^{2+}$. Especially for the solution with high iron content, more agitating barrels, steam, and compressed gas and a larger workshop area are needed, which dramatically increases the equipment investment and operation costs. Therefore, it is essential to improve the intake of oxygen, air, or oxygen-enriched air in the oxidization process, so as to increase the amount of dissolved oxygen in the solution and shorten the oxidation time of $\mathrm{Fe}^{2+}$ to $\mathrm{Fe}^{3+}$.

In general, in the hydrometallurgical industry's oxidation and iron removal industry, when compressed oxygen/air/oxygen-enriched air is introduced into the reaction tank using a gas distributor or a gas distributor device, the oxygen utilization rate is low, the ferrous ion oxidation rate is slow, and equipment costs and operating costs are high. This study proposes a new iron removal method based on strengthened oxygen oxidation of $\mathrm{Fe}^{2+}$ in solution by using a homemade venturi jet microbubble generator. It should be noted that this method is applicable for both leaching solutions and suspensions containing solid particles. Specifically, one or more venturi jet pipes are installed at the bottom or middle of the oxidation iron removal mixing tank and connected with the mortar pump through the pipeline. The mortar pump extracts the solution/suspension or other solutions in the mixing tank through the pipeline and pumps them into the venturi jet pipe. Due to the special structure of the venturi jet pipe, local negative pressure can 
be formed. Air/oxygen/oxygen-enriched air can be self-inhaled and then compressed into the iron removal mixing tank after fully mixing with the solution to form a large number of microbubbles. In this study, a venturi jet microbubble generator was built. The aim of this study is to elucidate the kinetics of air ferrous oxide. The effects of pump power, solution temperature, $\mathrm{pH}$, concentration of $\mathrm{Cu}^{2+}$, and solution flow rate on the oxidation performance of microbubbles towards $\mathrm{Fe}^{2+}$ were investigated. In addition, a highspeed camera was used to collect images of the produced microbubbles. In conclusion, the microbubble generator in this paper is an environmentally friendly process, with higher efficiency and less energy consumption, that achieves efficient $\mathrm{Fe}^{2+}$ removal in hydrometallurgy.

\section{Materials and Methods}

\subsection{Setup of the Experimental Device}

A horizontal variable-frequency centrifuge pump (Xinjie, BW4-4, Sunshine Pump, Shanghai, China) was connected with the water tank made of tempered glass through the venturi tube. An air inlet was arranged at the middle of venturi tube, through which air was blown into the solution when the centrifuge pump was working. The experimental setup is shown in Figure 1. A gas flowmeter was also installed to control the flow rate of the microbubble jet.

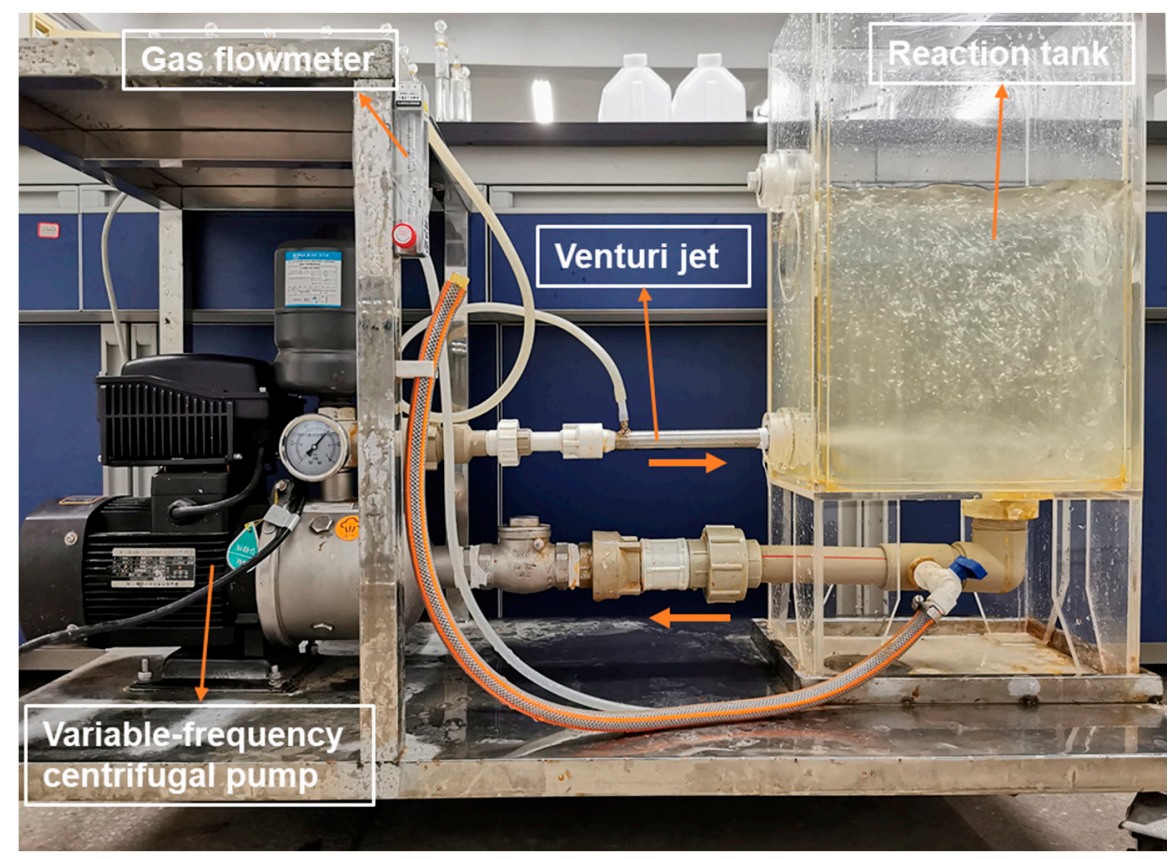

Figure 1. The homemade venturi jet microbubble generator.

\subsection{Experimental Methods}

The $\mathrm{FeSO}_{4}$ solution was prepared by dissolving a certain amount of $\mathrm{FeSO}_{4} \cdot 7 \mathrm{H}_{2} \mathrm{O}$ powder to make the concentration of ferrous ions $2 \mathrm{~g} / \mathrm{L}$ in the water tank containing $20 \mathrm{~L}$ of tap water. All experiments were conducted at natural temperature, except for the temperature condition experiments, and were repeated three times to get the average value. The residual concentration of $\mathrm{Fe}^{2+}$ in the solution after oxidation reaction was determined by chemical titration. It is widely reported that potassium permanganate $\left(\mathrm{KMnO}_{4}\right)$ can be used as the titrant to determine the concentration of $\mathrm{Fe}^{2+}[18] . \mathrm{KMnO}_{4}$ at $0.02 \mathrm{~mol} / \mathrm{L}$ was prepared. The flow rate of the microbubble jet was regulated with a gas flowmeter. The amount of dissolved oxygen in the solution was measured by a portable dissolved oxygen meter, and the microbubbles were imaged by a high-speed camera to analyze the size and quantity of the bubbles. It should be noted that, when measuring the concentration of $\mathrm{Fe}^{2+}$, 
the titration should be performed immediately after sampling, as oxygen in air can also dissolve in the sample solution to oxidize the $\mathrm{Fe}^{2+}$ ions.

\section{Results and Discussion}

\subsection{Influence of Different Jet Powers on Oxidation of Ferrous Ions}

Different jet powers of the microbubble generator will lead to different jet velocity and thus different air intake. The jet power of the multi-stage centrifuge pump was $0.75 \mathrm{~kW}$, and it was divided into gears 1 to 8 . To investigate the influence of the jet power, the gear of the pump was adjusted to $0(0 \mathrm{~kW}), 3(0.28 \mathrm{~kW}), 5(0.47 \mathrm{~kW})$, and $7(0.65 \mathrm{~kW})$. All experiments were performed at a solution $\mathrm{pH}$ of 5 and temperature of $25^{\circ} \mathrm{C}$. For comparison, the aeration-disc-produced air was also used. As shown in Figure 2, when the jet power was at gear 0 , the oxidation rate of ferrous ions in the solution was slow, and the concentration of ferrous ions in the solution decreased from $2000 \mathrm{mg} / \mathrm{L}$ to $1800 \mathrm{mg} / \mathrm{L}$ in $4 \mathrm{~h}$. When using the aeration disc, the oxidation rate of ferrous ions in the solution was improved, and the concentration of ferrous ions in the solution reduced to around 800 $\mathrm{mg} / \mathrm{L}$ after $1 \mathrm{~h}$ of reaction. It took almost $4 \mathrm{~h}$ for the ferrous ions to be completely oxidized. Further increasing the jet power to a higher gear (from gear 3 to 7 ), the oxidation rate of ferrous ions was much faster than that at gear 0 or when the aeration disc was used, and the concentration of ferrous ions in the solution reduced to much lower values. When the jet power was at gear 7 , the concentration of ferrous ions decreased to almost $0 \mathrm{mg} / \mathrm{L}$ within $40 \mathrm{~min}$ of reaction. It can be seen that the autooxidation rate of ferrous ions is very small compared to the operation of the microbubble generator. Overall, it is concluded that the homemade microbubble generating device could oxidize ferrous ions more efficiently. In addition, high jet power is beneficial for the complete oxidation of the ferrous ions.

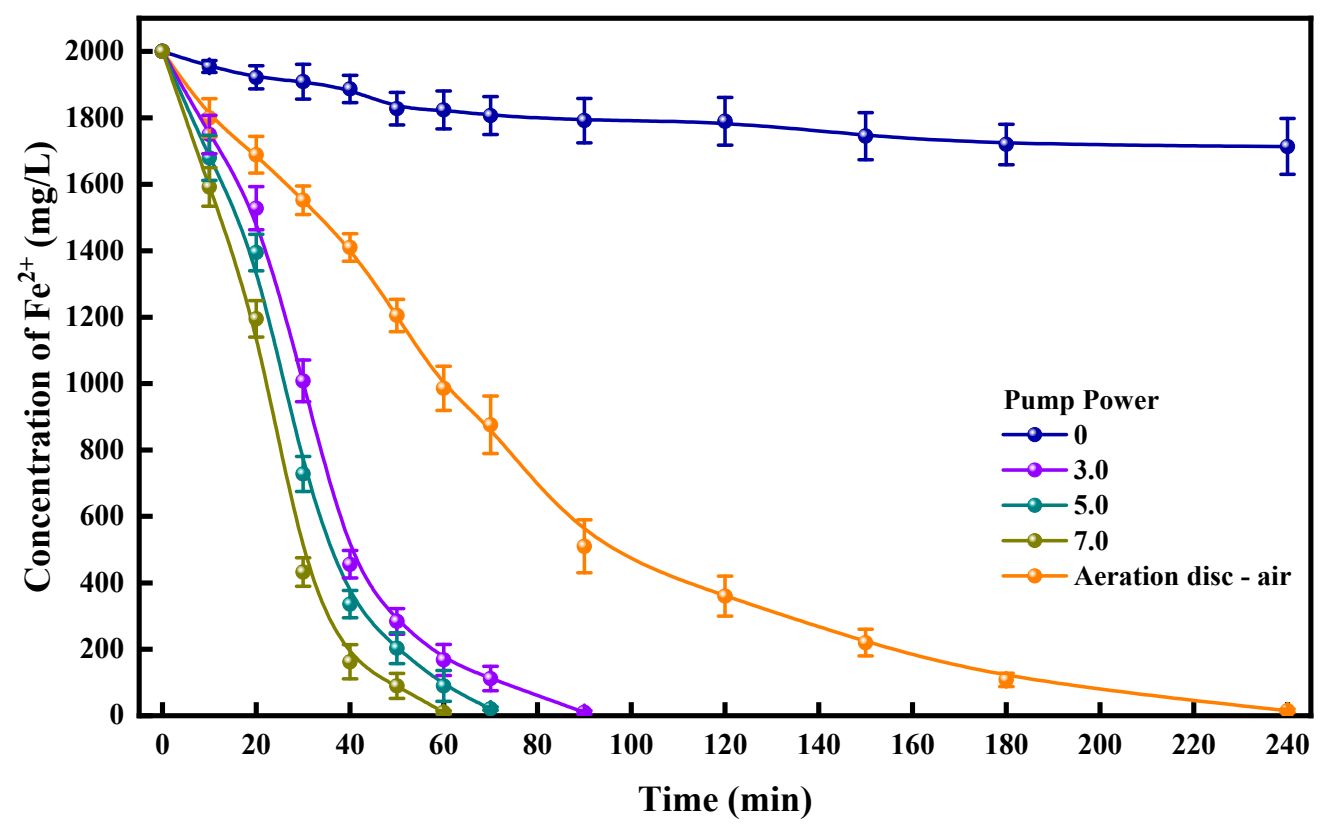

Figure 2. Influence of different powers on oxidation of ferrous ion.

The oxidation rates of ferrous ions for different methods of supplying oxygen were calculated based on the rate law (Equation (5)). Because the concentration of sulfate ions is relatively lower $(0.035 \mathrm{~mol} / \mathrm{L})$ in this system, all the ferrous ions were regarded as in the ionized state. Hence, the rate law of ferrous oxidation can be simplified as Equation (6):

$$
\frac{-d\left[\mathrm{Fe}^{2+}\right]}{d t}=k\left[\mathrm{Fe}^{2+}\right]^{2} P_{\mathrm{O}_{2}}\left(1+0.5\left[\mathrm{CuSO}_{4}\right]^{0.5}\right) e^{-9660\left(\frac{1}{T}-\frac{1}{423.15}\right)}
$$


The oxidation rate $(k)$ for different methods of supplying oxygen were calculated and are presented in Table 1 . The results indicate that, for the same oxygen partial pressure $\left(P_{\mathrm{O} 2}\right)$ and temperature $(T)$, the oxidation rate $(k)$ of ferrous ions by the venturi jet microbubble generator is 3.4-5.1 times greater than that by aeration disc.

Table 1. Oxidation rate $(k)$ for different methods of supplying oxygen.

\begin{tabular}{cccc}
\hline Jet Power & $\boldsymbol{k}$ & $\boldsymbol{R}^{\mathbf{2}}$ & Pearson's $\boldsymbol{r}$ \\
\hline 0 & $4.93 \times 10^{-7}$ & 0.92574 & 0.93541 \\
Aeration disc air & $3.67 \times 10^{-5}$ & 0.93669 & 0.94827 \\
3 & $1.23 \times 10^{-4}$ & 0.89814 & 0.91136 \\
5 & $1.24 \times 10^{-4}$ & 0.90462 & 0.91983 \\
7 & $1.89 \times 10^{-4}$ & 0.86032 & 0.88524 \\
\hline
\end{tabular}

\subsection{Influence of Temperature on the Oxidation of Ferrous Ions}

Normally, the increase of temperature will accelerate the chemical reaction rate, but the solubility of some substances, such as oxygen, will decrease. Thus, it is essential to investigate the effect of temperature on the oxidation rate of ferrous ions. In this study, the temperature of the solution was set to $25^{\circ} \mathrm{C}, 50{ }^{\circ} \mathrm{C}$, and $90^{\circ} \mathrm{C}$ under the jet power of gear three, and the results are summarized in Figure 3. It can be observed that by increasing the solution temperature from $25^{\circ} \mathrm{C}$ to $90^{\circ} \mathrm{C}$, the oxidation rate of ferrous ions increased significantly, and thus the time for complete oxidation of ferrous ions was greatly shortened. The complete oxidation time for ferrous ions at $25^{\circ} \mathrm{C}, 50^{\circ} \mathrm{C}$, and $90^{\circ} \mathrm{C}$ was $60 \mathrm{~min}, 50 \mathrm{~min}$, and $30 \mathrm{~min}$, respectively. Temperature is an important factor affecting the hydrolysis and precipitation of the metal ions. It has been widely reported that the hydrolysis of ferric ions is sensitive to temperature [19-21]. Therefore, it is inferred that the enhanced hydrolysis of the ferric ions at high temperature kept the concentration of ferric ions in the solution low so as to promote the oxidation of ferrous ions, though the solubility of oxygen decreased with the increase of temperature. Overall, high temperature is favorable for the oxidation of ferrous ions.

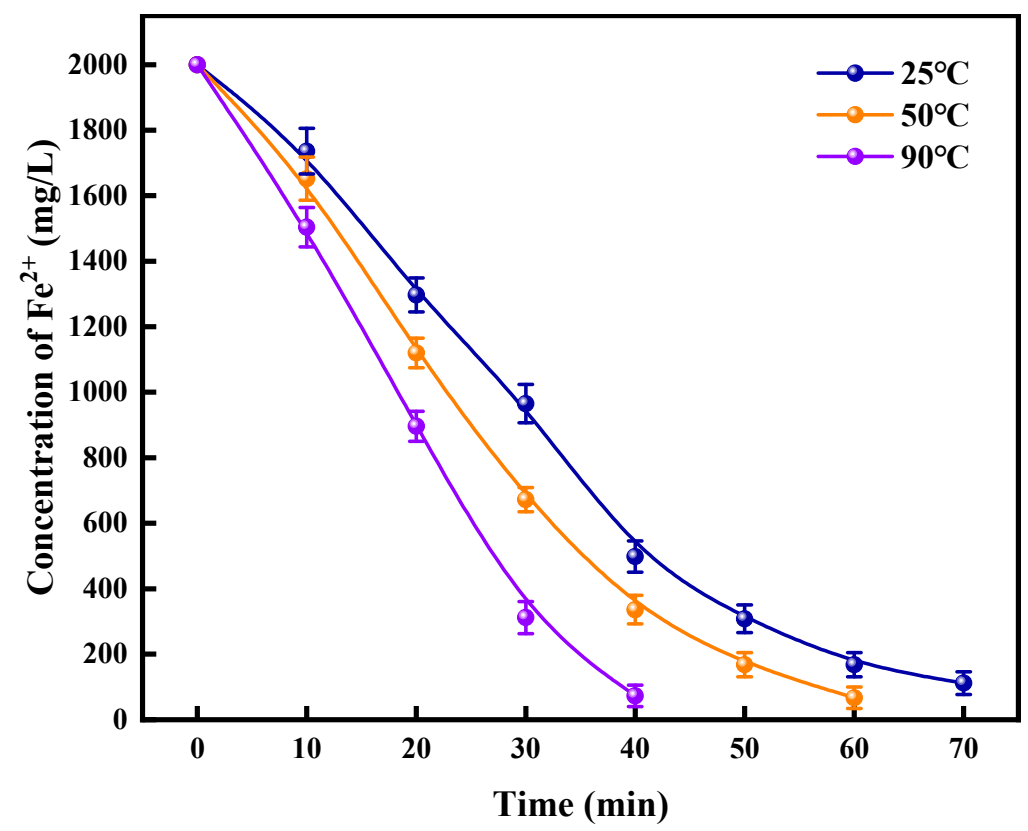

Figure 3. Influence of different temperatures on the oxidation of ferrous ions.

\subsection{Influence of Solution $\mathrm{pH}$ on the Oxidation of Ferrous Ions}

The $\mathrm{pH}$ of hydrometallurgical leaching suspension normally ranges from 2.5 to 6.5 . To study the effect of solution $\mathrm{pH}$ on the oxidation of ferrous ions, the $\mathrm{pH}$ was adjusted to 
4,5 , and 6 under a jet power of gear three and temperature of $25^{\circ} \mathrm{C}$. The results are shown in Figure 4. Generally, with the increase of the solution $\mathrm{pH}$, the oxidation rate of ferrous ions increased. When the solution $\mathrm{pH}$ was 4 , the reaction time for complete oxidation of ferrous ions was even more than $200 \mathrm{~min}$, indicating poor oxidation performance of the microbubbles towards ferrous ions under this condition. When adjusting $\mathrm{pH}$ of the solution to 5 or 6 , it only took $1 \mathrm{~h}$ or even less time for ferrous ions to be completely oxidized. At high $\mathrm{pH}$, the oxidation performance of the generated microbubbles was significantly improved, and the time for complete oxidation of ferrous ions was greatly shortened.

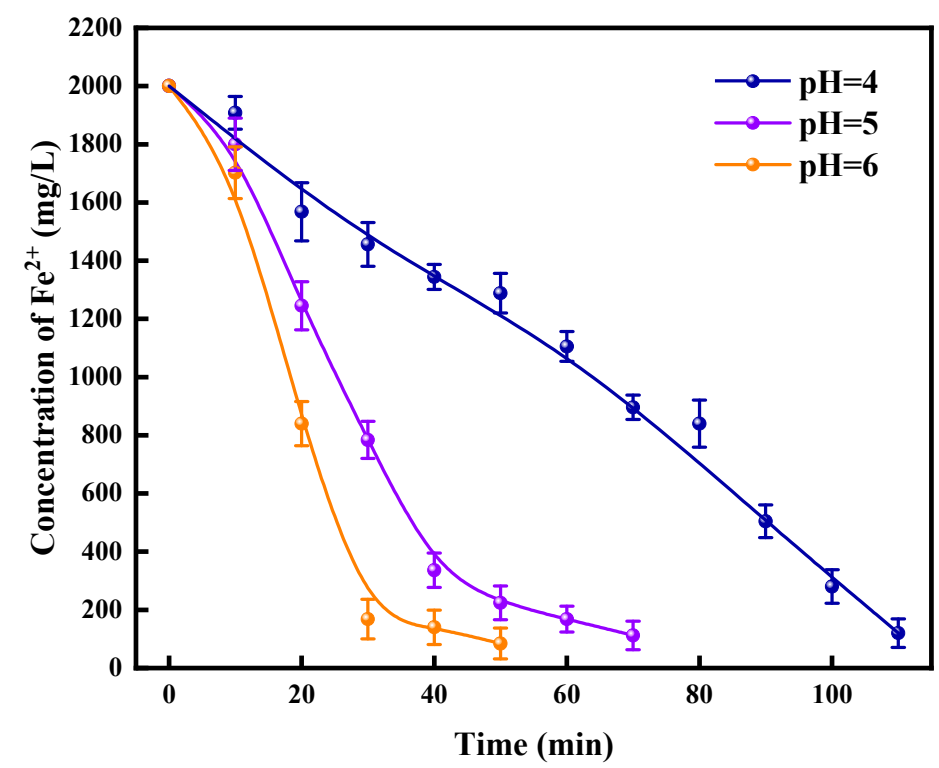

Figure 4. Influence of solution $\mathrm{pH}$ values on the oxidation of ferrous ions.

Figure 5 shows the regions and ranges of stable presence of ferrous ions in aqueous solutions. The two dashed lines marked with a and b symbols are the two E-pH curves for $\mathrm{H}_{2} \mathrm{O}$. It can be seen that the $\mathrm{pH}$ at which $\mathrm{Fe}(\mathrm{OH})_{3}$ starts to precipitate is about 1 , and the $\mathrm{pH}$ at which $\mathrm{Fe}(\mathrm{OH})_{2}$ starts to precipitate is about 6 . This indicates that no $\mathrm{Fe}(\mathrm{OH})_{2}$ precipitation was generated during this experiment, and the precipitate in the solution is all $\mathrm{Fe}(\mathrm{OH})_{3}$. Figure 5 provides an important thermodynamic basis for iron removal in hydrometallurgy. Therefore, $\mathrm{pH}$ played an essential role on the oxidation of ferrous ions.

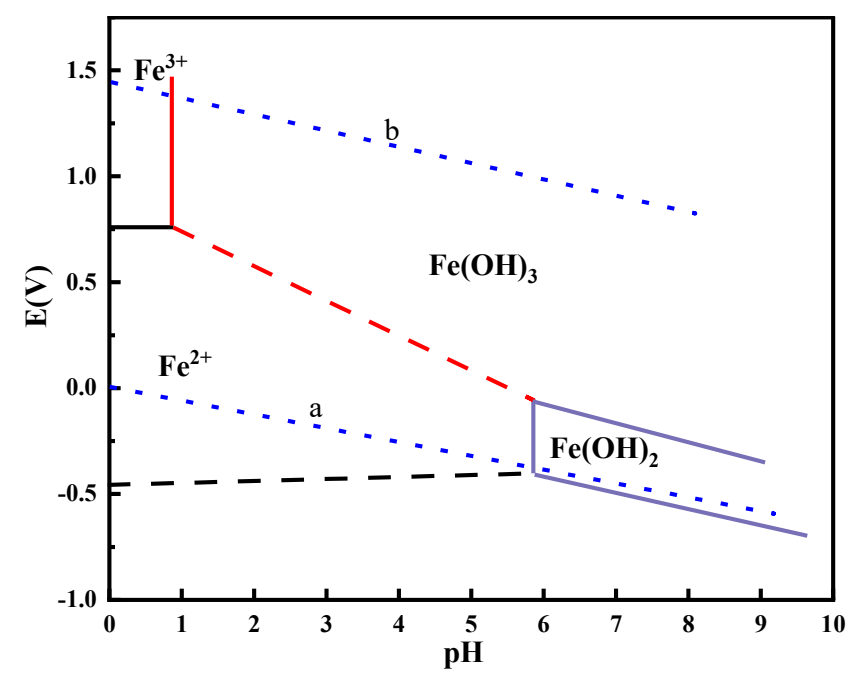

Figure 5. $\mathrm{Fe}-\mathrm{H}_{2} \mathrm{O}$ system E-pH. 


\subsection{Influence of Copper Ions on the Oxidation of Ferrous Ions}

According to the literature [22], the divalent copper ion was an effective catalyst for oxidation reactions. A total of $100 \mathrm{mg} / \mathrm{L}$ of the divalent copper ions was added into the solution to investigate whether the oxidation of ferrous ions could be improved, and the results are shown in Figure 6. The jet power was set at gear three, and the solution temperature and $\mathrm{pH}$ were $25{ }^{\circ} \mathrm{C}$ and 5 , respectively. In this study, the concentration of copper ions was $100 \mathrm{mg} / \mathrm{L}$, and copper hydroxide $\left(\mathrm{Cu}(\mathrm{OH})_{2}\right)$ precipitation was not generated. Therefore, the concentration of copper ions did not change during the oxidation reaction of ferrous ions. In the same reaction time, the concentration of ferrous ions with the addition of copper ions was always lower than that without the addition of copper ions, indicating that the divalent copper ions could catalyze and accelerate the oxidation of ferrous ions in the solution.

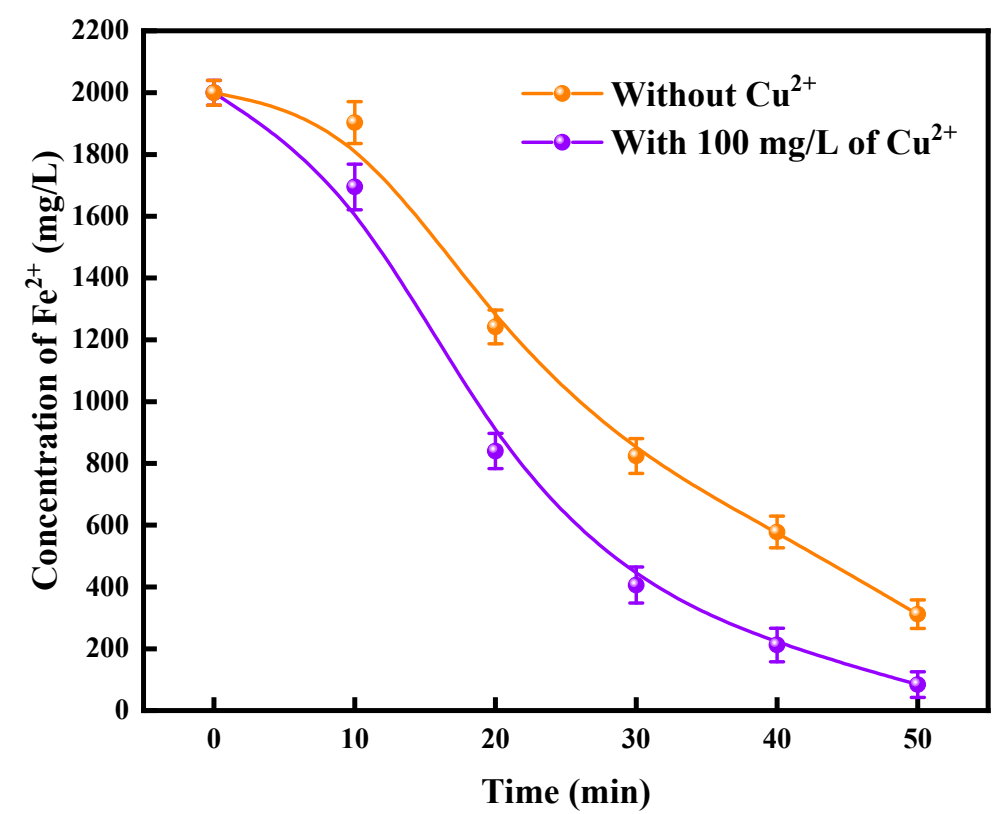

Figure 6. Influence of copper ions on the oxidation of ferrous ions.

\subsection{Influence of Microbubble Jet Flow Rate on the Oxidation of Ferrous Ions}

Different flow rates of the microbubble jet will produce different amounts of microbubbles, which will affect the oxidation of ferrous ions in the solution. The gas flowmeter was used to adjust the flow rate of the microbubble jet, and the effects of different flow rates on the oxidation of ferrous ions were explored. As shown in Figure 7, when the flow rate was $0 \mathrm{~L} / \mathrm{min}$ as a blank experiment, the oxidation reaction rate of ferrous ions was very slow, and the concentration of ferrous ions decreased from $2000 \mathrm{mg} / \mathrm{L}$ to $1200 \mathrm{mg} / \mathrm{L}$ after $50 \mathrm{~min}$ of reaction. By increasing the flow rate to $0.8 \mathrm{~L} / \mathrm{min}$, the concentration of ferrous ions in the solution reduced to about $200 \mathrm{mg} / \mathrm{L}$ in $50 \mathrm{~min}$. At higher flow rates of the microbubble jet, more bubbles could enter the reaction tank per unit time, which could increase the contact probability of ferrous ions with oxygen. Therefore, with the increase of the flow rate, the oxidation reaction rate of ferrous ions also increased. By comparing with the blank experiment, this further indicates that the microbubble generator can oxidize ferrous ions more efficiently. 


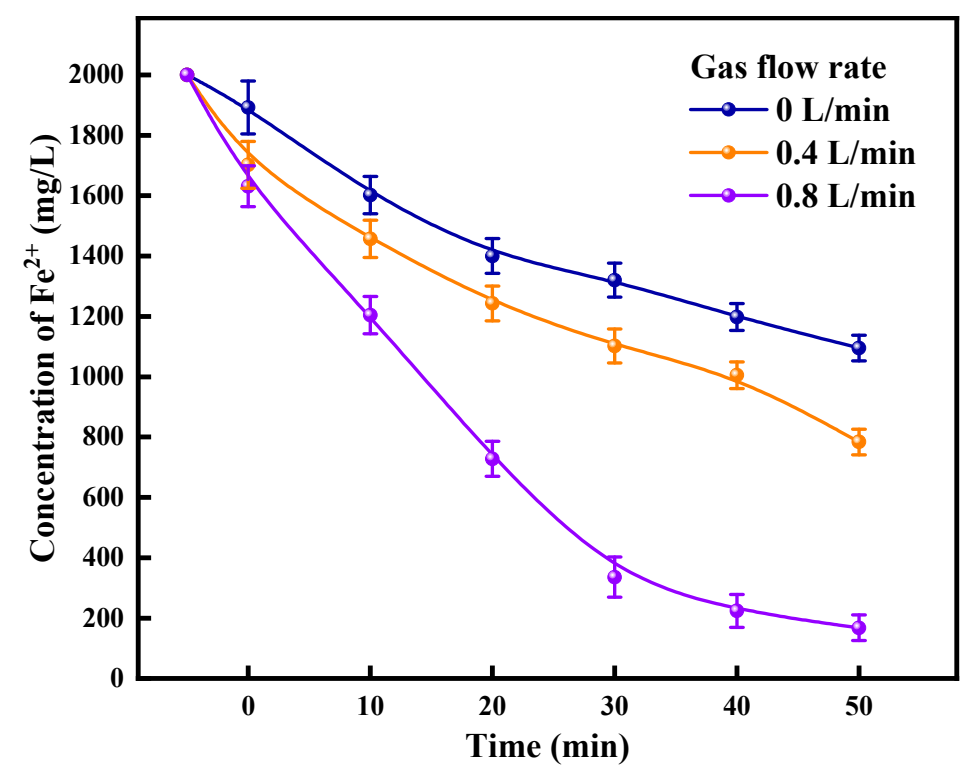

Figure 7. Influence of different flow rates on the oxidation of ferrous ions.

\subsection{Analysis of Dissolved Oxygen in the Solution}

In order to obtain more intuitive information about the generated microbubbles, a high-speed camera was used to collect images of the microbubbles, and the Image Pro Plus software was used to analyze the size and quantity of the microbubbles at different flow rates. Figure 8a-e shows the images of the microbubbles at different flow rates. With the increase of the flow rate from $0 \mathrm{~L} / \mathrm{min}$ to $0.8 \mathrm{~L} / \mathrm{min}$, it appears that the average size of the bubbles increased, which is likely due to the coalescence of the microbubbles. As shown in Figure 9, the average particle size and number of bubbles increased with the increase in flow rate. Though coalescence occurred at a high flow rate, the quantity of the bubbles in the solution was still more than that at a low flow rate. In other words, by adjusting the flow rate of the microbubbles, the size and quantity of the bubbles generated by the venturi microbubble generator will change. The increase in the bubble count could increase the contact probability between ferrous ions and bubbles in the solution, thus strengthening the oxidation of ferrous ions.

In order to further illustrate the influence of the microbubbles on the oxidation of ferrous ions, the amount of dissolved oxygen in the solution under different jet powers and flow rates was studied. The flow rate of the microbubble jet was adjusted using the gas flowmeter, and the dissolved oxygen content in the solution was measured by a dissolved oxygen meter.

The results in Figure 10 show that the amount of dissolved oxygen in the solution grew with the increase of the jet flow and power in general. When increasing the jet power from gear one to three, the dissolved oxygen content in the solution increased significantly and was also significantly higher than the aeration disc. Further increasing the jet power from gear three to seven, the dissolved oxygen content increased slightly under the same flow rate. Under a certain power, a slight increase in the dissolved oxygen amount was observed (see Figure 10) as the flow rate increased. This confirmed that with the increase of the flow rate, the oxidation reaction rate of ferrous ions increased as the dissolved oxygen amount increased, which was discussed in Section 3.5. The optimum jet power and flow rate for the oxidation of ferrous ions should be at gear $3 \sim 5$ and a flow rate of $0.6 \sim 0.8 \mathrm{~L} / \mathrm{min}$. 


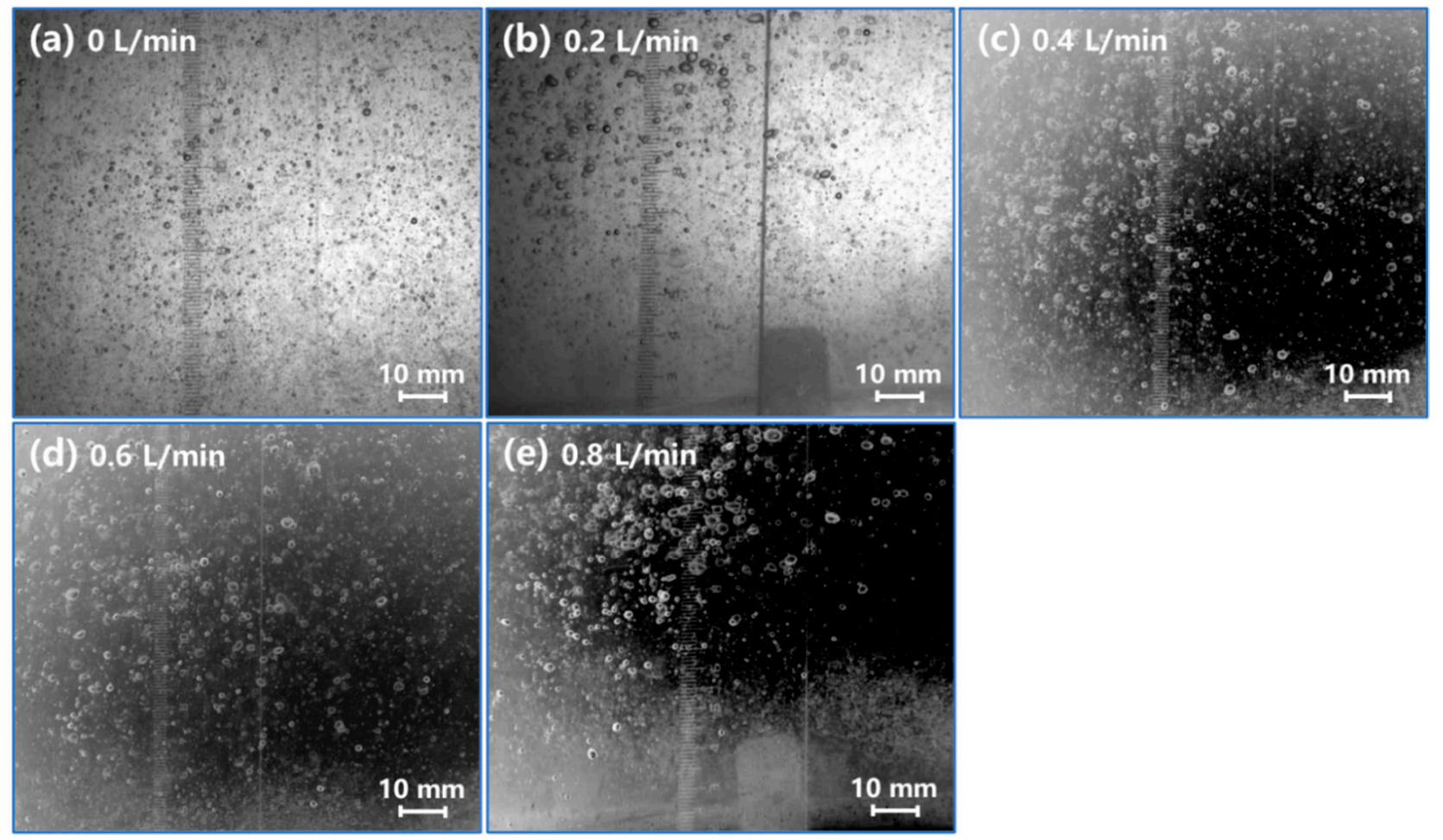

Figure 8. Images of the microbubbles and the corresponding size distribution at the flow rates of $0 \mathrm{~L} / \mathrm{min}(\mathbf{a}), 0.2 \mathrm{~L} / \mathrm{min}(\mathbf{b})$, $0.4 \mathrm{~L} / \mathrm{min}(\mathbf{c}), 0.6 \mathrm{~L} / \mathrm{min}(\mathbf{d})$, and $0.8 \mathrm{~L} / \mathrm{min}(\mathbf{e})$.

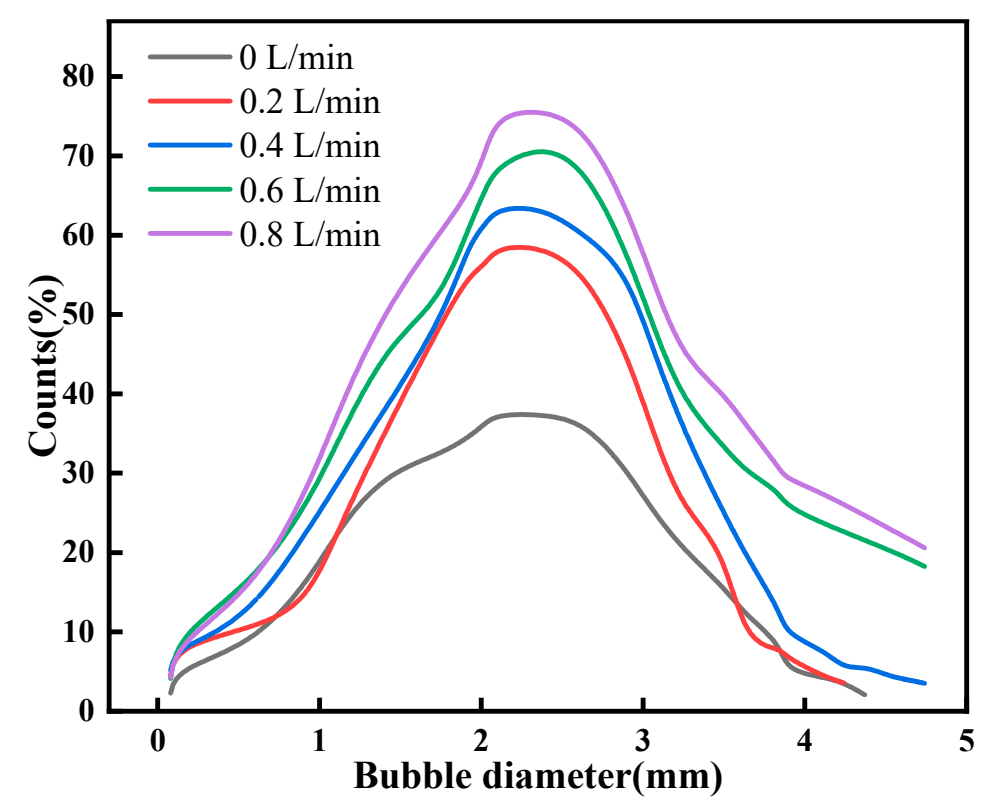

Figure 9. The surface particle size of bubbles at different flow rates. 


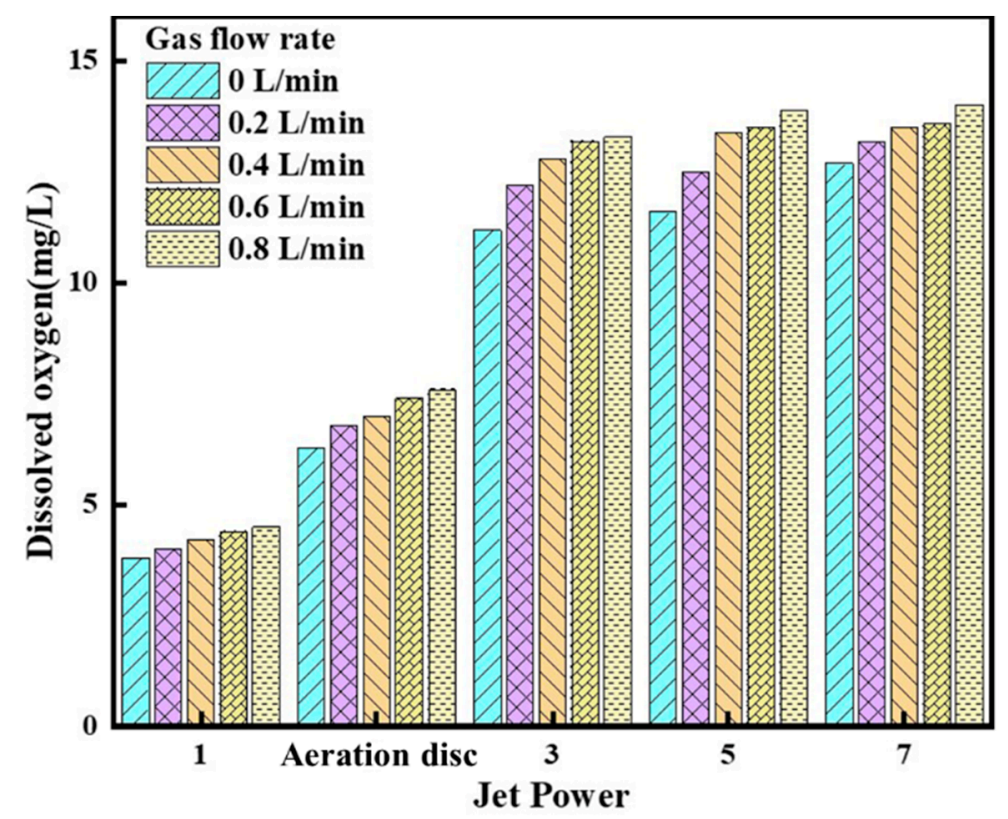

Figure 10. Dissolved oxygen amount in the solution at different jet powers and flow rates.

\section{Conclusions}

A venturi jet microbubble generator, which was used to produce microbubbles of oxygen, air, or oxygen-enriched air, was built for this study. The oxidation performance of the produced microbubbles was investigated. Both high jet power and high temperature $\left(90^{\circ} \mathrm{C}\right)$ can accelerate the oxidation rate of the ferrous ions by the microbubbles. When adjusting the $\mathrm{pH}$ of the solution to 5 or 6 , the time for complete oxidation of ferrous ions can be greatly shortened compared with that at $\mathrm{pH} 4$. Furthermore, the addition of the divalent copper ions $(100 \mathrm{mg} / \mathrm{L})$ can catalyze and enhance the oxidation of the ferrous ions in the solution. With the increase of the flow rate from $0 \mathrm{~L} / \mathrm{min}$ to $0.8 \mathrm{~L} / \mathrm{min}$, the oxidation reaction rate of ferrous ions also increased. The images of the microbubbles and the measurement results of the dissolved oxygen amount in the solution confirmed that the increase in the dissolved oxygen amount led to the enhanced oxidation of the ferrous ions, and the maximum dissolved oxygen amount can reach $14.4 \mathrm{mg} / \mathrm{L}$. Compared with traditional oxygen oxidation methods, such as using an aeration disk or aeration pipe to produce air bubbles, this method can significantly improve the oxygen utilization rate, shorten the iron removal time, increase the purification depth of iron ions, expand production capacity, and decrease energy consumption.

Author Contributions: Formal analysis, visualization, investigation, writing-original draft, X.F.; writing-review and editing, data curation, Z.N.; investigation, formal analysis, M.L. and Y.G.; conceptualization, funding acquisition, W.S.; methodology, project administration, resources, funding acquisition, supervision, writing-review and editing, T.Y. All authors have read and agreed to the published version of the manuscript.

Funding: This research was supported by the National Key Scientific Research Project of China (2019YFC0408305), National Natural Science Foundation of China (NSFC) (52104286), the Fundamental Research Funds for the Central Universities of Central South University Project (No. 2021zzts0892), and Hunan Provincial Natural Science Foundation of China (2021JJ40752).

Data Availability Statement: Data is contained within the article.

Acknowledgments: This work was carried out in Key Laboratory of Hunan Province for Clean and Efficient Utilization. We sincerely thank Zineng Chen for his technical support throughout the work.

Conflicts of Interest: The authors declare that they have no known competing financial interests or personal relationships that could have appeared to influence the work reported in this paper. 


\section{References}

1. Dutrizac, J.E.; Jambor, J.L. Jarosites and their application in hydrometallurgy. Rev. Mineral. Geochem. 2000, 40, 405-452. [CrossRef]

2. Ismael, M.R.C.; Carvalho, J.M.R. Iron recovery from sulphate leach liquors in zinc hydrometallurgy. Miner. Eng. 2003, 16, 31-39. [CrossRef]

3. Yue, T.; Niu, Z.; Tao, H.; He, X.; Sun, W.; Hu, Y.; Xu, Z. Green recycling of goethite and gypsum residues in hydrometallurgy with $\alpha-\mathrm{Fe}_{3} \mathrm{O}_{4}$ and $\gamma-\mathrm{Fe}_{2} \mathrm{O}_{3}$ nanoparticles: Application, characterization, and dft calculation. ACS Sustain. Chem. Eng. 2019, 7, 6821-6829. [CrossRef]

4. Loan, M.; Newman, O.M.G.; Cooper, R.M.G.; Farrow, J.B.; Parkinson, G.M. Defining the paragoethite process for iron removal in zinc hydrometallurgy. Hydrometallurgy 2006, 81, 104-129. [CrossRef]

5. Haakana, T.; Saxén, B.; Lehtinen, L.; Takala, H.; Lahtinen, M.; Svens, K.; Ruonala, M.; Gongming, X. Outotec direct leaching application in china. J. South. Afr. Inst. Min. Metall. 2008, 108, 245-251.

6. Deng, Z.; Yang, F.; Wei, C.; Zhu, B.; Zeng, P.; Li, X.; Li, C.; Li, M. Transformation behavior of ferrous sulfate during hematite precipitation for iron removal. Trans. Nonferrous Met. Soc. China 2020, 30, 492-500. [CrossRef]

7. Han, H.; Sun, W.; Hu, Y.; Tang, H. The application of zinc calcine as a neutralizing agent for the goethite process in zinc hydrometallurgy. Hydrometallurgy 2014, 147-148, 120-126. [CrossRef]

8. Han, J.; Liu, W.; Qin, W.; Jiao, F.; Wang, D.; Liang, C. Thermodynamic and kinetic studies for intensifying selective decomposition of zinc ferrite. Jom-Us 2016, 68, 2543-2550. [CrossRef]

9. Ruiz, M.C.; Zapata, J.; Padilla, R. Effect of variables on the quality of hematite precipitated from sulfate solutions. Hydrometallurgy 2007, 89, 32-39. [CrossRef]

10. Xing, Y.; Liu, H.; Deng, Z.; Wei, C.; Li, X.; Li, M.; Yang, Y. Dissolution behavior of ferrous sulfate in the hematite process. Hydrometallurgy 2021, 200, 105561. [CrossRef]

11. Zhou, L.; Peng, T.; Sun, H.; Hui, T. Mechanism and kinetics of iron removal in Fe-Al- $\mathrm{H}_{2} \mathrm{SO}_{4}$ system by coordination precipitation. J. Environ. Chem. Eng. 2021, 9, 105241. [CrossRef]

12. Niu, Z.; Li, G.; He, D.; Fu, X.; Sun, W.; Yue, T. Resource-recycling and energy-saving innovation for iron removal in hydrometallurgy: Crystal transformation of ferric hydroxide precipitates by hydrothermal treatment. J. Hazard. Mater. 2021, 416, 125972. [CrossRef] [PubMed]

13. Xiao, W.H.; Liu, X.H.; Zhao, Z.W. Kinetics of nickel leaching from low-nickel matte in sulfuric acid solution under atmospheric pressure. Hydrometallurgy 2020, 194, 105353. [CrossRef]

14. Baba, A.A.; Ibrahim, L.; Adekola, F.A.; Bale, R.B.; Ghosh, M.K.; Sheik, A.R.; Pradhan, S.R.; Ayanda, O.S.; Folorunsho, I.O. Hydrometallurgical processing of manganese ores: A review. J. Miner. Mater. Charact. Eng. 2014, 2, 230-247. [CrossRef]

15. Truong, G.L.; De Laat, J.; Legube, B. Effects of chloride and sulfate on the rate of oxidation of ferrous ion by $\mathrm{H}_{2} \mathrm{O}_{2}$. Water Res. 2004, 38, 2383-2393. [CrossRef]

16. Dreisinger, D.B.; Peters, E. The oxidation of ferrous sulphate by molecular oxygen under zinc pressure-leach conditions. Hydrometallurgy 1989, 22, 101-119. [CrossRef]

17. Huffma, R.E.; Davidson, N. Kinetics of the ferrous iron-oxygen reaction in sulfuric acid solution. J. Am. Chem. Soc. 1956, 78, 4836-4842. [CrossRef]

18. Vračar, R.Ž.; Cerović, K.P. Kinetics of oxidation of Fe(ii) ions by gaseous oxygen at high temperatures in an autoclave. Hydrometallurgy 1997, 44, 113-124. [CrossRef]

19. Yu, S.; Yang, B.; Fang, C.; Zhang, Y.; Liu, S.; Zhang, Y.; Shen, L.; Xie, J.; Wang, J. Dissolution mechanism of the oxidation process of covellite by ferric and ferrous ions. Hydrometallurgy 2021, 201, 105585. [CrossRef]

20. Lee, J.; Acar, S.; Doerr, D.L.; Brierley, J.A. Comparative bioleaching and mineralogy of composited sulfide ores containing enargite, covellite and chalcocite by mesophilic and thermophilic microorganisms. Hydrometallurgy 2011, 105, 213-221. [CrossRef]

21. Ruan, R.; Liu, X.; Zou, G.; Chen, J.; Wen, J.; Wang, D. Industrial practice of a distinct bioleaching system operated at low pH, high ferric concentration, elevated temperature and low redox potential for secondary copper sulfide. Hydrometallurgy 2011, 108, 130-135. [CrossRef]

22. Ren, M.; Xu, Q.; Bai, Y.; Wang, S.; Kong, F. Construction of a dual-response fluorescent probe for copper (ii) ions and hydrogen sulfide $\left(\mathrm{H}_{2} \mathrm{~S}\right)$ detection in cells and its application in exploring the increased copper-dependent cytotoxicity in present of $\mathrm{H}_{2} \mathrm{~S}$. Spectrochim. Acta A Mol. Biomol. Spectrosc. 2021, 249, 119-299. [CrossRef] [PubMed] 